\title{
Unbiased Whole-Genome Amplification Directly From Clinical Samples
}

\author{
Seiyu Hosono, A. Fawad Faruqi, Frank B. Dean, Yuefen Du, Zhenyu Sun, \\ Xiaohong Wu, Jing Du, Stephen F. Kingsmore, Michael Egholm, \\ and Roger S. Lasken ${ }^{1}$ \\ Molecular Staging, Inc., New Haven, Connecticut 06511, USA
}

\begin{abstract}
Preparation of genomic DNA from clinical samples is a bottleneck in genotyping and DNA sequencing analysis and is frequently limited by the amount of specimen available. We use Multiple Displacement Amplification (MDA) to amplify the whole genome 10,000-fold directly from small amounts of whole blood, dried blood, buccal cells, cultured cells, and buffy coats specimens, generating large amounts of DNA for genetic testing. Genomic DNA was evenly amplified with complete coverage and consistent representation of all genes. All 47 loci analyzed from 44 individuals were represented in the amplified DNA at between 0.5- and 3.0-fold of the copy number in the starting genomic DNA template. A high-fidelity DNA polymerase ensures accurate representation of the DNA sequence. The amplified DNA was indistinguishable from the original genomic DNA template in 5 SNP and 10 microsatellite DNA assays on three different clinical sample types for 20 individuals. Amplification of genomic DNA directly from cells is highly reproducible, eliminates the need for DNA template purification, and allows genetic testing from small clinical samples. The low amplification bias of MDA represents a dramatic technical improvement in the ability to amplify a whole genome compared with older, PCR-based methods.
\end{abstract}

DNA sample preparation is a rate-limiting step in genotyping analysis, and the common methods effectively limit the source of biological material that can be used for the extraction of DNA. Prior to isolating the genomic DNA (gDNA), the cells must be lysed and the DNA made available for extraction. The lysis often involves multiple steps of heating and cooling, proteinase $\mathrm{K}$ treatment, and alkaline lysis. Following lysis, a cartridge- or bead-based technique is typically used for the isolation of the gDNA. These procedures are timeconsuming and automation is difficult, limiting sample throughput. In a typical laboratory setting, significant variation is observed in the yield and purity of gDNA, which necessitates measuring and readjusting the concentration prior to use in genetic assays. Finally, the extensive manipulation can degrade DNA to various degrees.

Obtaining DNA from blood for large-scale studies can require large amounts of blood, special storage considerations, and may be limited by the need for trained personnel to obtain the sample. The invasiveness of blood-collection methods can limit voluntary participation of subjects, and there may also be cultural barriers to the procedures. Alternatively, DNA can be collected from cheek swabs. Buccal cells offer a simple and inexpensive alternative collection method ideal for large-scale population studies because it can be selfcollected and would allow simpler collection and sample handling in the physician's office. However, buccal cells have found limited utility because of the significant variation in yield and quality of the DNA obtained (Harty et al. 2000). Finally, buccal swabs would also be an ideal mode of sample collection for newborn screening because of the limited avail-

'Corresponding author.

E-MAIL rogerl@molecularstaging.com; FAX: (203) 776-5276.

Article and publication are at http://www.genome.org/cgi/doi/10.1101/ gr.816903. Article published online before print in April 2003. ability of infant blood. Alternatively, a method for DNA sample collection from very small blood samples would be useful, as this is readily obtained even from neonates by finger stick or heel prick.

Whole-genome amplification can generate a large amount of DNA directly from small cell samples as an alternative to DNA extraction and purification methods. Multiple Displacement Amplification (MDA) uses the $\$ 29$ DNA polymerase and random primers to amplify the entire genome (Dean et al. 2002). We have previously shown that phosphorothioate modification of primers dramatically stimulates the MDA reaction allowing amplifications of $10^{4}$ - to $10^{6}$-fold (Dean et al. 2001). The phosphorothioate nucleotides protect primers from degradation by the $3^{\prime}-5^{\prime}$ exonuclease proofreading activity of the $\phi 29$ DNA polymerase. The presence of an associated proofreading activity with the $\phi 29$ polymerase ensures high-fidelity amplification with an error rate of only $3 \times 10^{-6}$ (in mutations/nucleotide) in the amplified DNA (Nelson et al. 2002), compared with $\sim 1 \times 10^{-3}$ generated by Taq DNA polymerase in a PCR reaction (Dunning et al. 1988; Saiki et al. 1988).

Here we describe whole-genome amplification (WGA) by MDA for generating large quantities of high-quality, assayready DNA directly from clinical samples. The usefulness of a WGA method depends on its ability to represent the entire genome with minimal amplification bias. Large variation in the extent of amplification (Dean et al. 2002) occurring between different markers has limited the use of presently available PCR-based methods for whole-genome amplification such as DOP (Telenius et al. 1992) and PEP (Zhang et al. 1992). Amplification bias alters the information content of the DNA, making it an unreliable template for diagnostic testing. In the extreme case, regions of the genome are completely lost, resulting in allele dropout and diagnostic miscalls. Our initial 
report on whole-genome amplification by MDA demonstrated that eight different genetic markers analyzed were amplified to approximately equal extents (Dean et al. 2002). The faithful representation of the DNA template makes MDA suitable for generating genomic sequence for use in diagnostic or other laboratory applications. To demonstrate the broad applicability of the MDA method, the earlier studies were extended to an analysis of genetic markers spaced throughout the genome. In all, 47 different loci, one on each p and q arm of the 23 human chromosomes plus one locus on the Ychromosome, as well as common repetitive elements, were quantitatively assayed for the extent of amplification. The TaqMan quantitative PCR method was used to compare the relative loci copy number before and after amplification. The applicability of the MDA method has also been expanded to include sample preparation from a wide variety of biological sources. The performance of the amplified DNA as a template for accurate genotyping was confirmed. A rapid method is demonstrated for bypassing laborious sample preparation steps with DNA amplified from cells or blood being added directly to genetic assays.

\section{RESULTS}

\section{Amplification Directly From Cell Lysates}

MDA can be used to amplify the genome directly from biological samples such as blood and cells (Dean et al. 2002). To demonstrate the general applicability of MDA for preparing DNA from clinical specimens, samples were collected from 20 different individuals for cheek swabs (buccal cells), whole blood, and finger stick blood, and 6 individuals for buffy coat and Guthrie cards. In each case, MDA gave highly reproducible whole-genome amplification (Fig. 1). The amplified DNA was analyzed by the quantitative PCR TaqMan assay at eight different single-copy genomic loci. A value of $100 \%$ indicates that a locus is represented at the same copy number in the amplified DNA as in the starting genomic DNA template on a copy-per-microgram basis. No locus was represented at $<50 \%$ of its level in the human genome whether amplification was

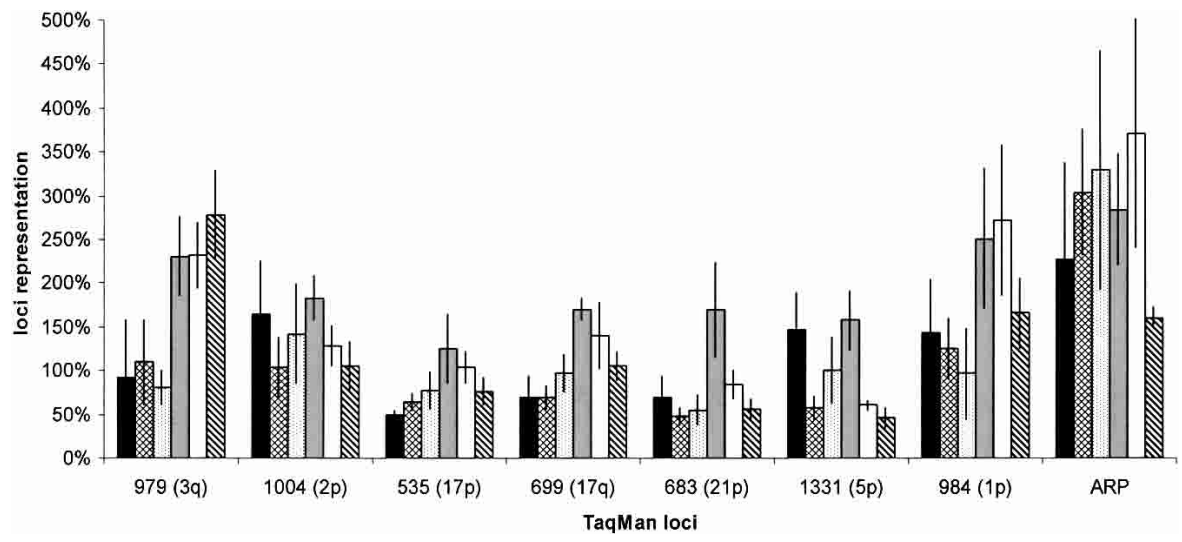

Figure 1 Comparison of MDA carried out from biological samples. Eight loci were examined for representation by the TaqMan assay. (Buccal swab) Black bars; (whole blood) cross-hatched bars; (finger stick) dotted bars; (buffy coat) gray bars; (Guthrie card) white bar; (control genomic DNA) diagonal-hatched bar. For buccal swab, whole blood, and finger stick blood, the error bar representing 1 SD was generated from the average of 20 different individual MDA amplifications. For buffy coat and Guthrie card, the error bar representing 1 SD was generated from the average of 6 different individual MDA amplifications. from the crude biological samples or the purified genomic DNA template control.

The ability to amplify from very small amounts of lysate avoids inhibition of the $\$ 29$ DNA polymerase. For example, heme in blood samples is known to inhibit some polymerase reactions (Higuchi 1995); however, use of just $0.05 \mu \mathrm{L}$ of blood in a $100-\mu \mathrm{L}$ MDA reaction volume (see Methods) eliminates any inhibitory effect. The $0.05-\mu \mathrm{L}$ blood sample contains $\sim 300$ total nucleated cells (containing about $1 \mathrm{ng}$ of genomic DNA), yielding a genomic amplification calculated to be $\sim 50,000$-fold (50- $\mu$ g DNA yield from $1 \mathrm{ng}$ of starting genomic template). Similarly, small starting samples of finger stick blood, buccal swab, Guthrie card, and buffy coat gave reproducible amplifications comparable to control amplifications using purified genomic DNA template. Reaction rates were also the same regardless of the sample amplified, yielding about a 10,000-fold amplification in 4-6 $\mathrm{h}$ (data not shown).

The amplified DNA can be added directly to subsequent genetic assays without the need for DNA purification procedures. For example, $2 \mu \mathrm{L}$ of the MDA reaction was added directly to the standard 50- $\mu \mathrm{L}$ TaqMan assay (Fig. 1). Even addition of $5 \mu \mathrm{L}$ of the MDA product per $50-\mu \mathrm{L}$ TaqMan assay did not inhibit the Taq polymerase because the calculated loci representation value was the same for $2 \mu \mathrm{L}$ or $5 \mu \mathrm{L}$ of MDA assayed ( $p=0.25$ ). Therefore, even when the amplified DNA is only diluted 10 -fold into PCR-type assays, it does not perturb the kinetics of the assay. The ability to bypass DNA sample purification steps gives MDA the potential to greatly simplify automated processes with amplification and downstream assay procedures directly from crude biological samples.

\section{Coverage and Bias Analysis of MDA Amplification of the Human Genome}

In order for MDA to be useful for DNA sample preparation, it must accurately amplify the genome without generating large bias in the extent to which different genes are represented. Initial studies showed that eight different genetic loci were amplified to about the same extent, whereas presently used PCR-based WGA methods had severe amplification bias ranging over 4-6 orders of magnitude, resulting in overrepresentation of some regions and loss of others (Dean et al. 2002). To validate MDA's utility for sample preparation, a comprehensive TaqMan analysis was carried out of 47 human loci, one from each of the $\mathrm{p}$ and $\mathrm{q}$ arms of the 22 human autosomes and $\mathrm{X}$-chromosome plus one locus on the Y-chromosome (Table 1 ). For each of the 47 loci, the variation in amplification performance was also compared for DNA obtained from 44 different individuals. The loci tested were randomly selected from a published database. All 47 of the loci were present in the MDA product within a few-fold of their representation in the genome (Fig. 2). Each bar represents the average for the 44 different DNA 
Table 1. DNA Sequence of the TaqMan Probes and PCR Primers of the 47 Loci Used in TaqMan Analysis for Genome Coverage and Bias

\begin{tabular}{|c|c|c|c|}
\hline $\mathrm{Chr}$ & WIAF & TaqMan Probes Sequence & TaqMan PCR Primer Sequence \\
\hline $1 p$ & 984 & TAGATTTCTTTGGACGAAGAAAATCCTTCTG & $L=\pi T T$ GATGGAGAAATCCGAGG R= CTGACTCGGAGAGCAGGAC \\
\hline $1 q$ & 695 & CACTGAAATATATTGCCTCCCAAATGATTCT & L= GGTAGGATGATTCTAGAATGCCA R= GCCCAAATTGGCTTCTIIT \\
\hline $2 p$ & 1004 & TGATGGCATTACTGGCACTTIGAGTTTTAC & L= GTCTTTAGCTGCTGAGGAAATG R= AGCAGAATTCTGCACATGACG \\
\hline $2 q$ & 99 & CTAATTTTGCTAATGCTGCGAGCATACCAT & L= AAAATAATTGAGTGGTATTTGGGC $\mathrm{R}=$ TTGGTGGGGTAAGCTCAGTC \\
\hline $3 p$ & 114 & CAGAAGGTAGAGAGCACCATGAAAGTACAG & $L=A T T$ ATTGCAAACTCCCTAATATCA R= CCTCCATTGGCATGAAGTCT \\
\hline $3 q$ & 979 & СТTСТTССТСТTСТСТСТСАСТGССАCGC & $L=$ AGAACCTGACCAGATGTGGC $R=$ CAAACGTCAAGCTCAGTTTCC \\
\hline $4 p$ & 1958 & ACTTAGGGAAATGTGGTTAGTGTGGTACGTT & $L=$ AACTGAATGGCAGTGAAAACA R= CCCTAGCCTGTCATTGCTG \\
\hline $4 q$ & 20 & TTCTCAGGCACCTCAATAAGACTTAAGGTG & L= TATAGCCCACCTGACCCAAG R= CTGTCATCACTGTCTACTTCCTCTC \\
\hline $5 p$ & 1331 & CTGGAAGTTCCAACTGTGCACTGAG & L= GGGTAAGATCCAGAGCCACA R= CCTCATTCCTTCTCGAAGCA \\
\hline $5 q$ & 1561 & CATTTCTGGAGCTGGTAGGAATAACC & L= GGAACAATACTACCTAAGGACAA R= AGTTTGCAACTTAAATCTCAGTT \\
\hline $6 \mathrm{p}$ & 857 & TGCCCTAATGCAAAGACTAGAATACTGCTTTC & $L=\pi T C T C \pi T G C T T A G C C A G C T R=$ AGGCCTATAGCTAGAGGACTGATA \\
\hline $6 q$ & 397 & ATTTGCCACGTCTTCCTCAGTAGAATAAGAC & L= TGCTITTAAAAATAACAATGACCA R= ATAGGCCAAATGTCCCTCCT \\
\hline $7 p$ & 349 & ATGAGTTCCTTCTCGTTAAGTGCTGGATATACTT & L= AAGAAAAGCACATACATTTCCAG R= AGTTGTCCGGAATCCCTCC \\
\hline $7 q$ & 1478 & AATCCCAGCTGCAATGCAAACTG & $L=\pi T C C C A C T C A A A A C T C C C A C R=$ ACAGGAATGAGGGCAGCTAA \\
\hline $8 p$ & 724 & CCAAGTGCTAAAGCAGTTTTAATAACAGGTTC & $L=T A A G T G C A T T A A C T G T A C A A G T C C A R=C A C A T C T T C A A T A T T A T G G A A A A C A$ \\
\hline $8 q$ & 441 & CTGGTTGTCGAGCAGTCTTACTCCTTGG & L=AGAGGGGAGATTCCCAGTGT R= CTCAGTGACCACTTIGTCAAGC \\
\hline $9 p$ & 870 & ACATCATGTTTACCTGTGCAGGCACTA & L= TGAAACCGTTTCAACATGGA R= TATCAGCATGGTCATCTGTAAAGG \\
\hline $9 q$ & 578 & AGTTGCCATCTGCGTGACAATAAA & $L=T T C T G A A A A T A T A A C C A G C C A T T G \quad R=$ ACCATTTCACATTTATTTGAAAGC \\
\hline 10p & 966 & CTGTACAGTGAATGGTGCCATTTTCGA & L= GTTCTGCTGCCTCTACACAGG R= ATCCTTCTGTGAACTCTCAAATCC \\
\hline $10 \mathrm{q}$ & 723 & ACTGTIITTGAAGGCTCTGTCTCAGTATCTG & L= CTTCCTGACCTGTTGCAGT R= CTTCAGTGCACAGAATGCAG \\
\hline $11 \mathrm{p}$ & 622 & CGTTGTTAGAGCAACCCCAGAAAATT & $L=$ TGTTTAAAACCATACAGTTTGTGC R= AATAGTTAAAAGAGGGCAGAAAAA \\
\hline $11 q$ & 379 & САCTCCCTGCCCATTCCCTATAAGAATATC & $\mathrm{L}=\mathrm{GCTCTAGTGGGAAACCTCAGG} \mathrm{R=} \mathrm{GAATTCCAGGCTCTTGCTTG}$ \\
\hline $12 p$ & 1805 & AGTCCCTGCAGCAGAAGATGCCAA & $L=$ CCACACACTCTGG $\Pi \Pi$ ATAAAGC $R=\Pi \Pi \Pi T C T C C T G C A T C C A T G G$ \\
\hline $12 q$ & 1726 & AGTAACAACGACCTAGAAAAGTGAGAACA & L= TCCTCATTGTTGGGGATGAT R= TGGCCAAAAATAGAAGCCAT \\
\hline $13 p$ & 474 & ACTTGTTCATCTTCTGACCGTTTGCTG & L= CTCCCTTCCTATGTCTCTCAGC R= TACCATTACCTCGAAATGTACGT \\
\hline $13 q$ & 911 & TGACCTATCTCACCAAGCGAGAGG & $L=$ TTAAATCAGTCGTAACCCTCCC R= GGCGAGGCTATGATAAACCA \\
\hline 14p & 2000 & CACTGATGAGGCAGTAAACTACATAGGG & L= TATTGGTATGCTTAGGGAAGATTC R= CAGGAAGCATGATTCCAGAT \\
\hline $14 q$ & 646 & AGCGAGGAGCCAACTATCCCAAATATAC & L= GCAGAGAAGAGAACCATGCC $R=\pi I I I T$ AAGAGTTGCAACAATTCA \\
\hline $15 p$ & 163 & TGAAGAAACACTGACATTCAGGAAAAGC & $L=$ AAAAGCC $\Pi T A T T$ TAAGGACTGAGC $R=$ TTCAACATAACACCCTTGAATCC \\
\hline $15 q$ & 244 & AGCAGATATTCTTTCATGGGTTATTTTGC & $L=$ GAGTTTAATGAATCCTGTTCCCC R= CTGTAATATAACCGTTTCATTCAGC \\
\hline $16 p$ & 789 & TGTCAAAAAATGTTTGCCTGATTCTAATCA & $L=$ ACGGAGTCGTCTCTGATGTATT R= TITTGTGTTTTTCATGACATTGA \\
\hline $16 q$ & 974 & AGGCAAGTCCACAGGTCACACTTGTC & $L=$ ATAACTAGGGAGAAAACCAAACTG R= CCTCTAACTGCCTCGACGAC \\
\hline 17p & 535 & TGAGGCTTTIGTACTITAGTAAATGCTTCCAC & $L=$ CCCAGATGTGCCCATCAC R= ATCAAGCCTTGTGTTCTGACA \\
\hline $17 q$ & 699 & TGAACTGCTCCTTGGCAGGGATTT & L= TGCTCCCTGTCCCATCTG R= AGACAGTATGCCTITATTCACCC \\
\hline $18 p$ & 525 & CTGATTCTITGGTCACACAGGGACTTC & L= GAAACTATCCTTTAGTGGTGCCA R= AAAGGAACAATCCTGTCAGGC \\
\hline $18 q$ & 929 & CCTAATGTCAGATAACTAAATTACTTCCTAGGTTTTCA & L= GAAGGAAAAGGGTAGCATGG R=ACAATCCTGTTCATAGAGTAAGCA \\
\hline $19 p$ & 893 & AGATTATTCTGAAGTGGAAACCACCCT & L= GATCCAATCTCAGTGTCTAACTCA R= TTGAGGCAATAATCCAGCT \\
\hline $19 q$ & 972 & TGGGTTGCCAGCTCCAATGTAC & L= CAAAGTTGTCTCCTGCCCAT R=ACCTTAGACATTTGTAAGCAAGGG \\
\hline $20 p$ & 1684 & TGAAACTGCAGGGCAAGAGGAGTGA & $L=A C C C A G C T C C T C T$ ACCCTC $R=$ GCAATAGTTACGACTGTGGGC \\
\hline $20 q$ & 265 & TGACAAGGCCAGGCAATTITATTTG & $\mathrm{L}=$ ATTGTATGCCAAAATCATAATACCC $\mathrm{R}=$ GACAGTATGTATGATGGTCAGCC \\
\hline $21 \mathrm{p}$ & 683 & CAATTCAATGTTGTGGGCACTG & L= TGAGGCTATGATTGCAGATTI R= TCCCTAAATGACAAAAAGAGAAGG \\
\hline $21 q$ & 1537 & AGCCTAAATGATGAATGGTGCGC & L= TGTTIGTGTTCCAGCCACAT R=CTCTCAGTTAGCAGCTGGGC \\
\hline $22 p$ & 1874 & CCGATITGCAGGCAGTGCTTTCTAAACT & 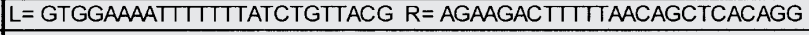 \\
\hline $22 q$ & 498 & CATATGGTGACTTGATGACCCAGAGTC & $L=$ TATACCACT TCCATTTGATGATGG R= CCCAGCAGATCCAATGTTG \\
\hline$x_{p}$ & 137 & TGTTCTCTCTGCCTGCACTGG & L= AGAATTCATCTACAATTCCTCCG R=ATTTGAGACATCTTGGCTTTTACC \\
\hline $\mathrm{Xq}$ & 707 & TGAGATTCACTTCTTAGAAGCACTGGCTATGTAC & 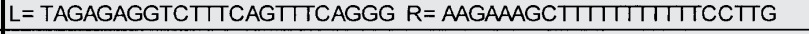 \\
\hline $\mathrm{Y}$ & SRY & CGAAGATGCTGCCGAAGAATTGC & L= TACAGGCCATGCACAGAGAG R= TAAGTGGCCTAGCTGGTGCT \\
\hline
\end{tabular}

The loci are one from each of the $\mathrm{p}$ and $\mathrm{q}$ arms of the 22 human autosomes and $\mathrm{X}$-chromosome plus one locus on the $\mathrm{Y}$-chromosome.

samples. Loci representation for the amplified DNA was determined relative to a genomic DNA standard. Loci representation values ranged between about $50 \%$ and $300 \%$ of the levels in the starting genomic template, a maximum of a sixfold bias between any two loci. Therefore, for these 47 loci, all in single-copy genes, none was represented at less than half a copy or more than 3 copies per genome following the amplification. The variation from sample to sample was also low, with a standard deviation (Fig. 2, error bars) between the 44 individuals tested ranging from $\pm 16 \%$ to $39 \%$ for the 47 loci tested. The complete graphs of all of the data for the 44 autosomal loci and $2 \mathrm{X}$-chromosomal loci give a visual representation of the accuracy with which the amplified DNA con- serves the original genomic ratio of markers (Fig. 3). Each graph is for one of the loci tested, and each bar represents one of the 44 subjects tested. The minor variation between loci was reproducible, with some loci consistently being represented at higher levels than others (Figs. 2, 3). Therefore, the particular sequence content of a locus apparently results in a low level of reproducible amplification bias. For the Y-chromosome-specific locus SRY (Figs. 2, 3), only MDA from the 22 out of 44 subjects $(50 \%)$ resulted in a detectable signal consistent with interrogation of a Y-chromosome marker.

Another use of the loci representation data is in evaluating the specificity of the MDA reaction for amplifying ge-

\section{Genome Research}




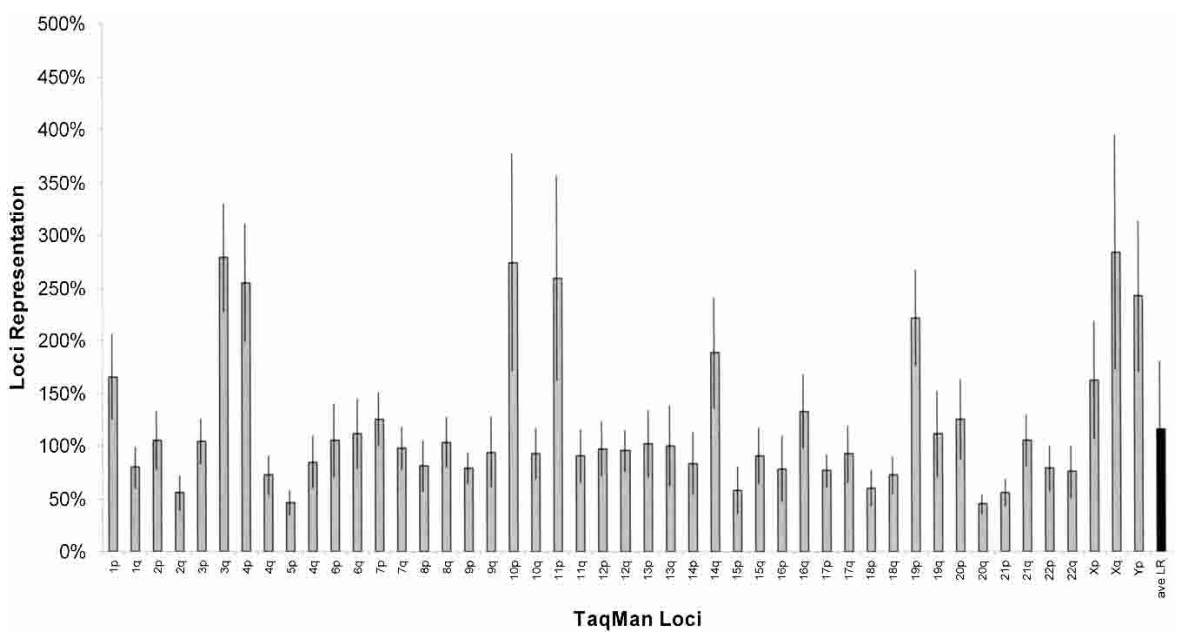

Figure 2 Amplification bias analysis by the TaqMan assay for 47 human loci. The location on the chromosome for the 47 loci tested from the WIAF (Whitehead Institute-Affymetrix) SNPs database (http://www-genome.wi.mit.edu/snp/human/) is in Table 1. Loci representation relative to the starting DNA template for each of the 47 loci. Each bar represents the average loci representation of 44 patients. The average of all of the 47 loci was $117 \%$ (black bar).

nomic sequence. The average representation summed up over all 47 loci should be $100 \%$ in the ideal case in which only genomic sequence is amplified free of any nonspecific sequence such as primer dimers or other amplification artifacts. The presence of artifact sequence will be correspondingly reflected in an average of less than 100\%. The average of all of the 47 loci tested (Fig. 2, black bar) is $117 \%$, consistent with a highly specific amplification of genomic sequence. One explanation for why the average could be slightly higher than $100 \%$ is that some repetitive sequences such as the centromere and telomere repeats are lost in the amplified DNA (Dean et al. 2002). Whereas the MDA reaction appears to predominantly generate genomic sequence, PCR-based WGA products can contain up to $70 \%$ amplification artifacts (Cheung and Nelson 1996; Dean et al. 2002).

\section{Coverage and Bias Study of LINE and SINE Human Repetitive Sequences}

In contrast to coding sequences, telomeric and centromeric repetitive sequences are not amplified by the MDA method (Dean et al. 2002). Other sequences referred to as interspersed repeat elements were amplified by MDA based on TaqMan analysis (Fig. 4). Long interspersed nuclear elements (LINE-1) are 6-7-kb, retrotransposon-like pseudogenes representing $\sim 17 \%$ of the total human genome (Smit 1996). These had a representation of $\sim 74 \%$ relative to the starting genomic template (Fig. 4A). The 44 independent MDA reactions were carried out from a set of human genomic DNA from Coriell Institute with a standard deviation of $\pm 19 \%$. The short interspersed nuclear elements (SINE) represented by the Alu sequence are also a retrotransposon-like pseudogene $\sim 300 \mathrm{bp}$ long accounting for $\sim 10 \%$ of the total human genome (Weiner 1980; Ullu and Tschudi 1984). Representation of the SINE element was $\sim 71 \%$ of the level in the genome with a standard deviation of $\pm 16 \%$ (Fig. 4B). Therefore, the amplified DNA had $\sim 7 \times 10^{5}$ copies per genome compared with $\sim 1 \times 10^{6}$ copies known to be in the human genome.

\section{Accurate Genotyping From MDA Amplified DNA}

The utility of the MDA method depends on its ability to accurately conserve genomic sequence. The ф29 DNA polymerase, a highfidelity proofreading enzyme, assures a low replication error rate (Esteban et al. 1993; Nelson et al. 2002). The ability to accurately genotype point mutations and SNPs was tested for the wholegenome amplifications from buccal swabs, whole blood, and finger stick blood collected from 20 different volunteers (Fig. 1). In each case, the amplified DNA was compared with unamplified genomic DNA that was extracted from an aliquot of the blood specimens using a conventional DNA purification kit (Methods). A SNP TaqMan assay was carried out for allelic discrimination on five loci (Table 2) with automated genotype scoring by the ABI 7000 using its Sequence Detection System (SDS) software. Complete concordance between amplified DNA and conventionally purified DNA was found for whole blood (100/100), finger stick blood (100/100), and buccal swab (100/100). The accurate conservation of genomic sequence by MDA also allows assay of sequence repeat number in microsatellite DNA. Again, the amplified DNA was compared with the conventionally purified DNA for genotyping of nine tetranucleotide short tandem repeats (STR) and the Amelogenin locus. Analysis by capillary electrophoresis indicated accurate genotyping with no increase in stutter bands for the amplified DNA (Fig. 5). Also, the two parental alleles of heterozygous loci were amplified by MDA to about equal extents because the ratio of peak heights between alleles is not significantly altered between amplified and unamplified DNA. Overrepresentation of one allele over another could result in allele dropout artifacts, with heterozygotes being miscalled as homozygotes. There was complete concordance (Table 3) between genotypes of all 10 of the loci from amplified and conventionally purified DNA from 20 individuals for whole blood (200/200), finger stick blood (200/200), and buccal swab (200/ 200).

\section{DISCUSSION}

A major limitation to the adoption of nucleic acid testing in routine clinical settings has been inconsistent sample preparation methods and DNA constraints. MDA is a simple and reliable method that meets the growing demands for highthroughput DNA preparation. Whole-genome amplification generates large quantities of DNA from limiting samples while eliminating the need for purification steps based on centrifugation, chaotropic agents, solvents, alcohols, and DNA-drying procedures. Amplification of genomic DNA directly from clinical samples also eliminates much of the risk of contamination in downstream purification processes. Buccal swabs, whole blood, Guthrie cards, and buffy coat were indistinguishable from purified DNA as starting samples for the am- 


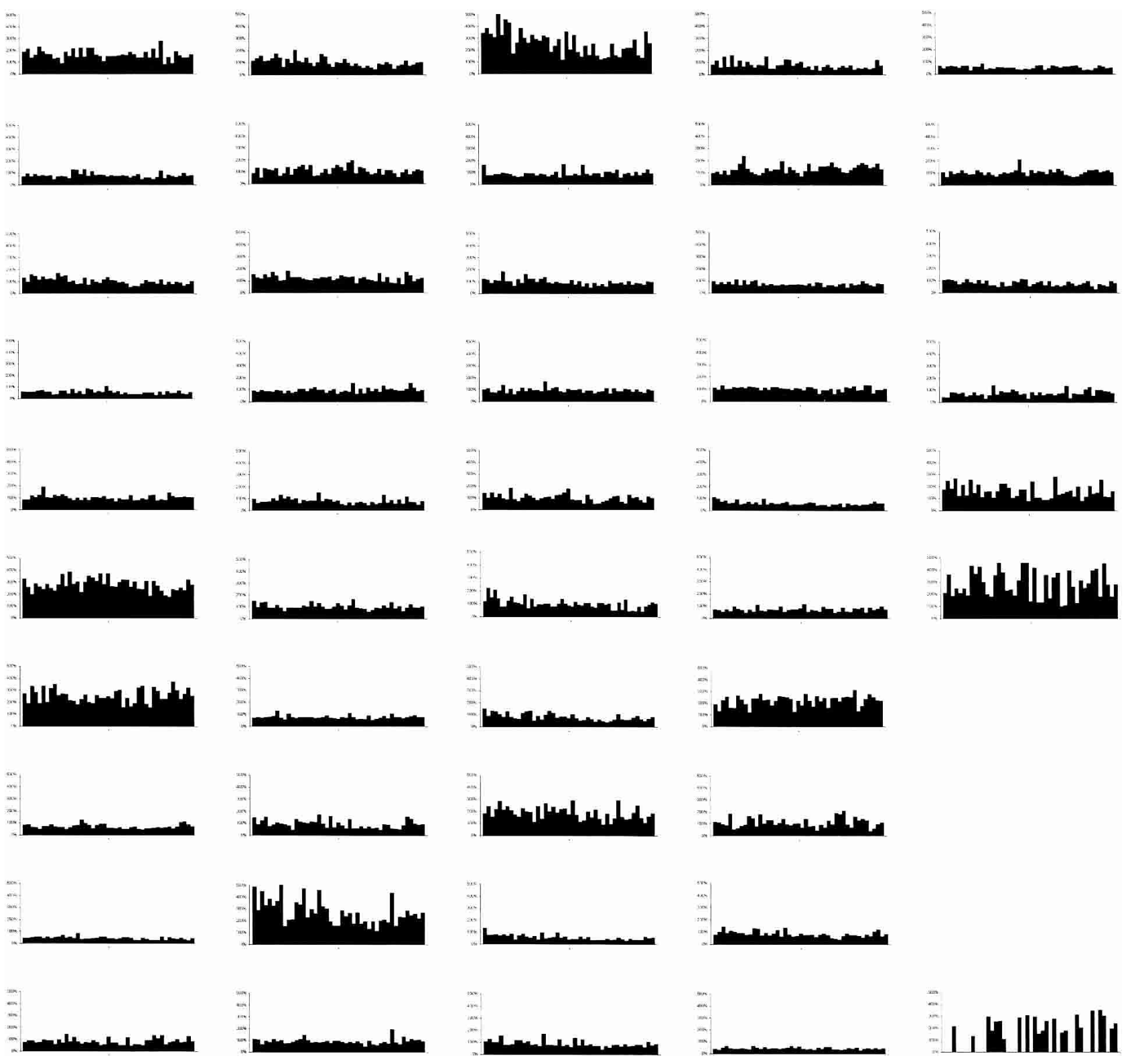

Figure 3 Histograms of loci representations for 47 genetic Loci and 44 DNA samples. Each graph is for a different locus, with each bar representing one of the 44 DNA samples. The loci representation for the Y-chromosome-specific sex determining region gene (SRY) is depicted in the bottom right-hand corner.

plification (Fig. 1). The highly robust activity of the $\phi 29$ DNA polymerase ensures uniform yields regardless of the type of clinical material amplified. $\$ 29$ DNA polymerase has extremely tight binding to the DNA template and a high rate of strand displacement synthesis through virtually any DNA sequence and secondary structure (Blanco et al. 1989). Amplification from a small number of cells effectively dilutes out contaminants that can inhibit an amplification such as heme in blood or sample additives like EDTA. For example, $0.05 \mu \mathrm{L}$ of blood is added to a $100-\mu \mathrm{L}$ MDA, giving a 2000 -fold dilution of the blood in the MDA reaction. A 10,000-fold or greater amplification resulting from MDA enriches the DNA relative to the contaminants. This enrichment exceeds the purity gained with common DNA purification products and allows use of MDA-generated templates directly in a wide range of genetic assay formats.

A comprehensive bias analysis confirmed relatively uniform amplification of the genomic DNA template across the genome. Of the 47 loci tested by the TaqMan quantitative PCR method, a maximum sixfold bias occurred between any two loci (Figs. 2 and 3). No locus was represented at $<50 \%$ of its level in the starting DNA template. A similar bias study performed on MDA amplification directly from five different biological sample types using eight TaqMan loci showed a level of bias similar to that found for the complete analysis of 47 loci using purified genomic DNA (Fig. 1). MDA directly from gently lysed cells avoids the DNA template loss and damage that can occur if DNA is purified prior to amplifica- 

Kunkel 1991) with accumulation of about one mutation per 900 bases after 20 PCR cycles (Saiki et al. 1988). The accumulation of mutations following a 10,000-fold am-

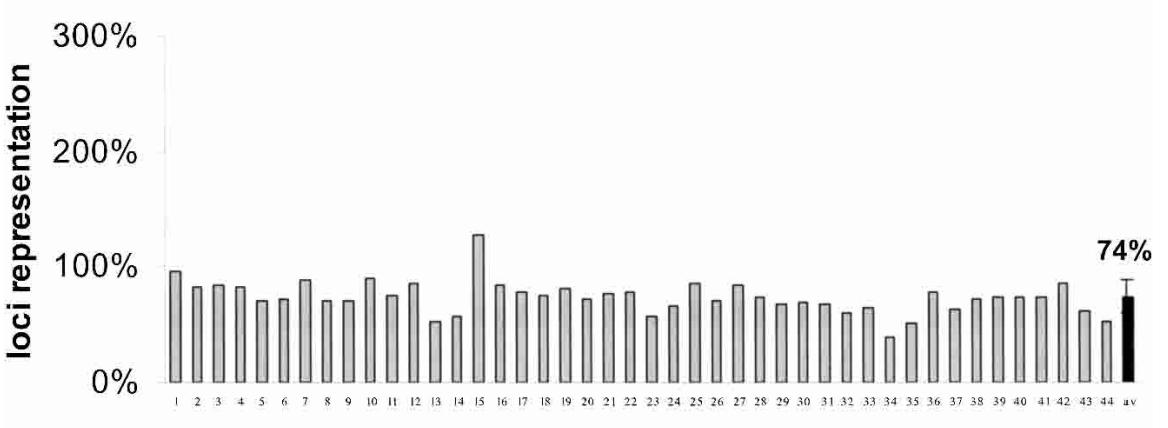
plification by MDA is only 3 per $10^{6}$ nucleotides (Nelson et al. 2002).

High-fidelity amplification by MDA ensures accurate genotyping in downstream applications regardless of the type of clinical sample used including whole blood, finger stick blood, and buccal swabs. To test genotyping accuracy, blood and cell samples were collected from 20 different volunteers for whole-genome amplification by MDA. For a control, DNA was purified from the blood samples with a conventional spin cartridge purification method. The MDA-amplified DNA performed identically to unamplified DNA in 10 STR (Table 3) and 5 SNP (Table 2) genotyping assays on three different sample types from 20 individuals. Heterozygous loci are useful for determining allele dropout, and it is notable that the 12 heterozygous SNPs and the 153 heterozygous STRs were all in complete agreement with the reference DNA. MDA-amplified DNA is also

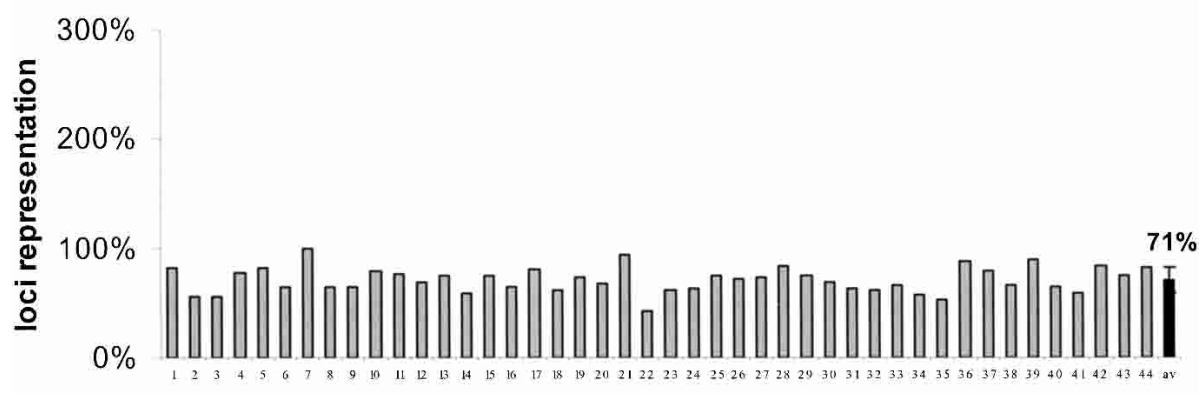

44 individual genomic DNA samples

Figure 4 Loci representation for repetitive elements. (A) Long interspersed nuclear element (LINE); (B) short interspersed nuclear element (SINE).

tion. Amplification from cells apparently allows efficient MDA from even smaller amounts of template (estimated at $\sim 1$ ng DNA from 300 nucleated cells) compared with use of purified DNA, and avoids the increased amplification bias that can result from degraded DNA template (Dean et al. 2002). The reliable representation of essential sequences is a prerequisite for accurate genetic testing. Earlier attempts at wholegenome amplification based on PCR with random (Zhang et al. 1992) or degenerate (Cheung and Nelson 1996) primers suffer from large amplification bias (Dean et al. 2002) and frequent allele dropout in diagnostic applications (Paunio et al. 1996). In contrast, MDA-amplified DNA appears to be of high enough quality for use in most genetic testing applications. An exception would be gene dosage measurements, in which further validation will be necessary.

MDA also benefits from use of a high-fidelity, proofreading DNA polymerase that accurately conserves DNA sequence information. The $\phi 29$ DNA polymerase has a very low error rate of 1 in $10^{6}-10^{7}$ nucleotides both in its intrinsic enzymatic activity (Esteban et al. 1993) and during the amplification reaction (Nelson et al. 2002) in contrast to $\sim 3$ in $10^{4}$ for Taq compatible with mutation genotyping with the GeneScorer assay, a ligation and rolling circle amplification method (O. Alsmadi, C. Bornarth, W. Song, M. Wisniewski, J. $\mathrm{Du}$, J. Brockman, A. Faruqi, S. Hosono, Z. Sun, Y. Du, X. Wu, M. Egholm, P. Abarzúa, R. Lasken, and M. Driscoll, in prep.). Microsatellite DNA analysis demonstrates conservation of the number of repeats in the amplified DNA. Successful genotyping by 9 STR repeats and Amelogenin loci is significant, because on average, combination of these loci gives about 1 in 5 billion probability of identity. The $\phi 29$ DNA polymerase accurately conserved the repeat number free of stutter bands that can result from slippage of the polymerase on microsatellite sequences in PCR. The tetranucleotide repeats in the ABI Profiler Plus system performed at Genaissance Pharmaceuticals demonstrates conservation of STR alleles. Additional testing of the accuracy of genetic assays using MDA-generated DNA template is planned.

We have incorporated a simple sample preparation procedure into the MDA process to make it compatible with high-throughput processes. The steps of cell lysis in $\mathrm{KOH}$, neutralization with Tris- $\mathrm{HCl}$, and assembly of MDA reactions can all be carried out with an automated pipetting station in a microtiter plate format. The MDA reaction tends to be selflimiting, generating a constant amount of DNA regardless of the amount of starting template (Dean et al. 2002). Constant DNA yields from any amount of starting clinical sample simplifies automated MDA reaction setup and delivery of ampli- 
Table 2. Genotyping of Five SNP Loci on MDA-Amplified Product From Whole Blood, Finger Stick Blood, and Buccal SWAB

\begin{tabular}{|c|c|c|c|c|c|c|c|c|}
\hline \multirow{2}{*}{$\begin{array}{l}\text { Sample } \\
\#\end{array}$} & \multirow[b]{2}{*}{ CYP2C $19 * 2$} & \multirow[b]{2}{*}{ CYP2D6*8 } & \multirow[b]{2}{*}{ CYP2C $19 * 3$} & \multirow[b]{2}{*}{ CYP2D6*6 } & \multirow[b]{2}{*}{ CYP2D6*4 } & \multicolumn{3}{|c|}{ Concordance with gDNA } \\
\hline & & & & & & WB & FP & BS \\
\hline 1 & GA & GG & GG & no deletion & GG & $100 \%$ & $100 \%$ & $100 \%$ \\
\hline 2 & GG & GG & GG & no deletion & GG & $100 \%$ & $100 \%$ & $100 \%$ \\
\hline 3 & GG & GG & GG & no deletion & GG & $100 \%$ & $100 \%$ & $100 \%$ \\
\hline 4 & GA & GG & GG & no deletion & GG & $100 \%$ & $100 \%$ & $100 \%$ \\
\hline 5 & GA & GG & GG & no deletion & GG & $100 \%$ & $100 \%$ & $100 \%$ \\
\hline 6 & $\mathrm{AA}$ & GG & GG & no deletion & GG & $100 \%$ & $100 \%$ & $100 \%$ \\
\hline 7 & GA & GG & GG & no deletion & GG & $100 \%$ & $100 \%$ & $100 \%$ \\
\hline 8 & GA & GG & GG & no deletion & GG & $100 \%$ & $100 \%$ & $100 \%$ \\
\hline 9 & GA & GG & GG & no deletion & GG & $100 \%$ & $100 \%$ & $100 \%$ \\
\hline 10 & GG & GG & GG & no deletion & GG & $100 \%$ & $100 \%$ & $100 \%$ \\
\hline 11 & GG & GG & GG & no deletion & GG & $100 \%$ & $100 \%$ & $100 \%$ \\
\hline 12 & GG & GG & GG & no deletion & GG & $100 \%$ & $100 \%$ & $100 \%$ \\
\hline 13 & GG & GG & GG & no deletion & GA & $100 \%$ & $100 \%$ & $100 \%$ \\
\hline 14 & GG & GG & GG & no deletion & GG & $100 \%$ & $100 \%$ & $100 \%$ \\
\hline 15 & GG & GG & GG & no deletion & GG & $100 \%$ & $100 \%$ & $100 \%$ \\
\hline 16 & GA & GG & GA & no deletion & GG & $100 \%$ & $100 \%$ & $100 \%$ \\
\hline 17 & GG & GG & GG & no deletion & GA & $100 \%$ & $100 \%$ & $100 \%$ \\
\hline 18 & GA & GG & GG & no deletion & GG & $100 \%$ & $100 \%$ & $100 \%$ \\
\hline 19 & GG & GG & GG & no deletion & GG & $100 \%$ & $100 \%$ & $100 \%$ \\
\hline 20 & GA & GG & GG & no deletion & GG & $100 \%$ & $100 \%$ & $100 \%$ \\
\hline
\end{tabular}

The first column shows the sample ID number of the 20 individuals tested. The next five columns show the five loci tested for genotyping, which were CYP2C19*2 (G/A), CYP2D6*8 (G/T), CYP2C19*3 (G/A), CYP2D6*6 (T deletion), and CYP2D6*4 $(\mathrm{G} / \mathrm{A})$, by TaqMan assay for allelic discrimination. The small table on the right shows the percentage genotype concordance with the genomic DNA control for the biological specimens tested. (WB) Whole blood; (FP) finger stick; (BS) buccal swab.

fied DNA to downstream applications. Biological samples can be processed without measuring or adjusting the starting cell concentration, with consistent DNA yields feeding directly to downstream assays with no need to measure and readjust the amplified DNA. About $67 \mu \mathrm{g}$ of DNA $( \pm 1$ Standard Deviation of $5 \mu \mathrm{g}$ ) was generated in a $100-\mu \mathrm{L}$ MDA when DNA template ranged from $10 \mathrm{pg}$ (about three genomic copies) up to $10 \mathrm{ng}$ or more (data not shown). Amplification yield was unchanged when MDA was performed directly from biological materials (data not shown). This finding is consistent with the observation (Dean et al. 2002) that the DNA yield is independent of the input amount of DNA template owing to a self-limiting characteristic of MDA in which DNA synthesis ceases at a certain concentration of DNA product. Consistent highfidelity yields give MDA the potential for integration and standardization of all preanalytical DNA sample processing of clinical samples.

Conventional DNA sample preparation methods effectively limit the source of biological material that can be tested. It is frequently not feasible to assay small samples by genetic tests, particularly when multiple assays and genetic markers are involved. Generation of EBV transformed cells lines is an alternative approach for generating unlimited sample but is costly and time-consuming. Whole-genome amplification from cells eliminates this limitation. MDA could be used for large-scale studies and diagnostic screening using buccal swabs or blood samples collected by finger or heel stick. These less-invasive methods can simplify sample collection, handling, and storage, with MDA generating large quantities of DNA for testing of multiple markers. MDA should be useful for a number of other applications in which a limited amount of cells are available. DNA could be generated for embryo preimplantation genetic diagnosis (Holding and Monk 1989), sperm or oocyte typing (Li et al. 1988), laser capture microdissection (Emmert-Buck et al. 1996), and needle aspirate biopsies (Euhus et al. 2002).

MDA should be ideal for large population studies such as the Cancer Genome Project. Recently, genome-wide screens have been used to identify genes involved in the disease process (Davies et al. 2002). However, this approach uses DNA from cultured tumor cells. Some of these cells, such as those from prostate and pancreatic cancers, are difficult to culture (Pollock and Meltzer 2002). In addition, cultured cell lines accumulate mutations over time and may not truly reflect the genetic make-up of the original tumor cells. MDA would allow amplification directly from tumor cells without the costly and labor-intensive process of generating cell lines. The recent analysis of Chromosome 21 by high-resolution microarray scanning (Patil et al. 2001) and the imminent prospect of whole-genome association studies underscore the need for sufficient quantities of DNA sample. MDA is a fully scalable reaction generating $7 \mathrm{mg}$ of DNA in a 10-ml reaction (data not shown), sufficient for the needs of high-throughput nucleic acid testing of multiple markers, reference samples for QC assays, and long-term sample archiving.

\section{METHODS}

\section{DNA and Enzymes}

For the comparison of MDA from 44 different purified genomic DNA templates for the bias and RFLP analysis, DNA 

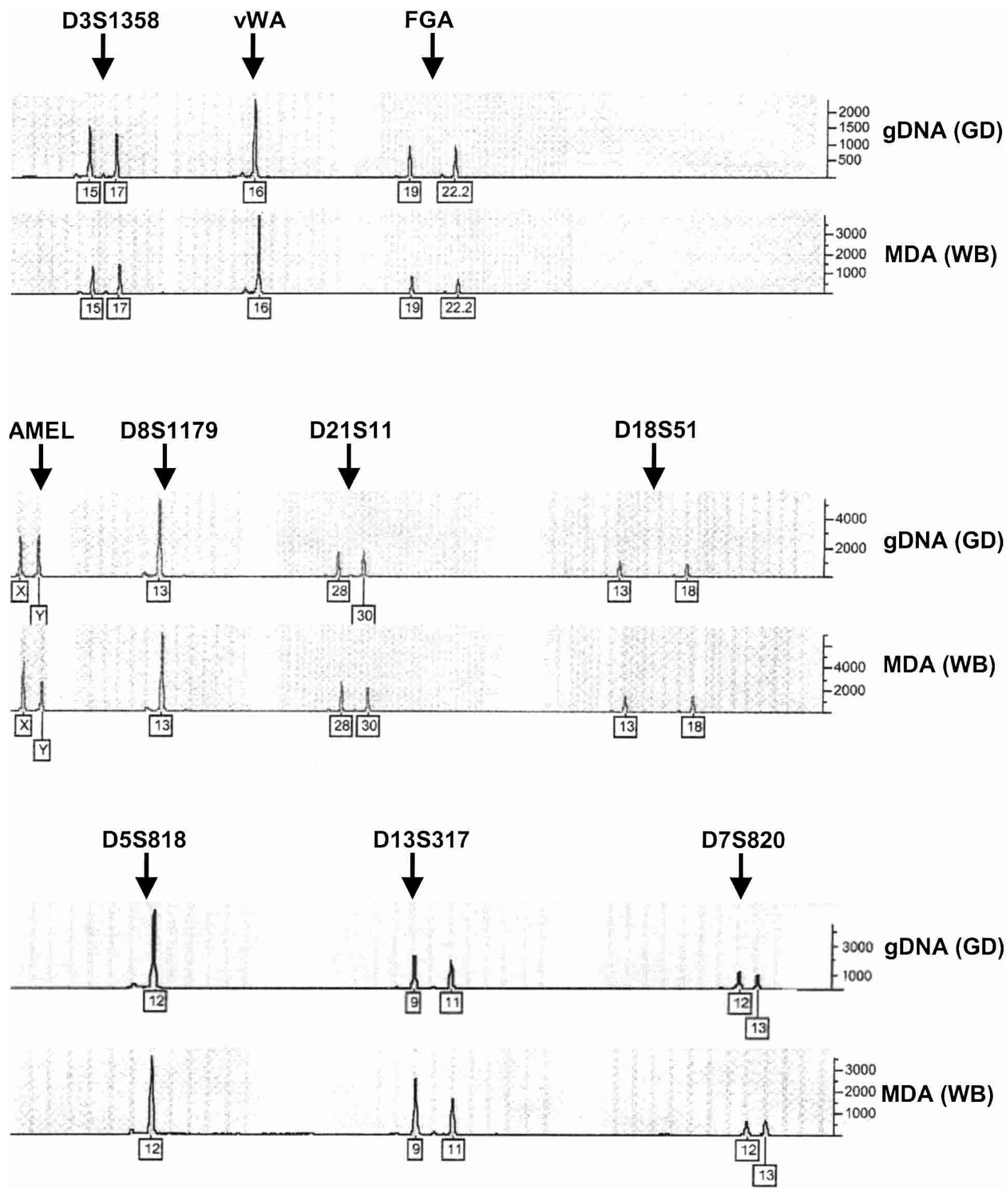

Figure 5 Representative GeneScan software electropherograms of ABI AmpFLSTR Profiler Plus STR analysis. MDA-amplified DNA from whole blood (Table 3, sample \# 6, WB) was compared with the conventionally purified DNA (Table 3, sample \# 6, GD) for genotyping of 9 tetranucleotide short tandem repeats (D3S1358, vWA, FGA, D8S1179, D21S11, D18S51, D5S818, D13S317, D7S820) and the Amelogenin locus. 
Table 3. Genotyping of Nine STR Loci and Amelogenin Locus on MDA-Amplified Product From Whole Blood, Finger Stick Blood, and Buccal Swab

\begin{tabular}{|c|c|c|c|c|c|c|c|c|c|c|c|c|c|c|c|c|c|c|c|c|c|c|c|}
\hline \multirow{2}{*}{$\begin{array}{l}\text { Sample } \\
\#\end{array}$} & \multicolumn{2}{|c|}{ D3S1358 } & \multicolumn{2}{|c|}{ vWA } & \multicolumn{2}{|c|}{ FGA } & \multicolumn{2}{|c|}{ D8S1179 } & \multicolumn{2}{|c|}{ D21S11 } & \multicolumn{2}{|c|}{ D18S51 } & \multicolumn{2}{|c|}{ D5S818 } & \multicolumn{2}{|c|}{ D13S317 } & \multicolumn{2}{|c|}{ D7S820 } & \multicolumn{2}{|c|}{ AMEL } & \multicolumn{3}{|c|}{$\begin{array}{l}\text { Concordance } \\
\text { with gDNA }\end{array}$} \\
\hline & 1 & 2 & 1 & 2 & 1 & 2 & 1 & 2 & 1 & 2 & 1 & 2 & 1 & 2 & 1 & 2 & 1 & 2 & 1 & 2 & WB & FP & BS \\
\hline 1 & 14 & 16 & 17 & 18 & 27 & 27 & 16 & 17 & 29 & 33.2 & 12 & 18 & 9 & 11 & 13 & 13 & 11 & 11 & $X$ & Y & $100 \%$ & $100 \%$ & $100 \%$ \\
\hline 2 & 14 & 16 & 16 & 19 & 20 & 22 & 12 & 15 & 28 & 31 & 15 & 16 & 11 & 12 & 9 & 12 & 9 & 10 & $X$ & $Y$ & $100 \%$ & $100 \%$ & $100 \%$ \\
\hline 3 & 16 & 18 & 14 & 18 & 21 & 22 & 15 & 15 & 29 & 32 & 15 & 19 & 11 & 12 & 11 & 12 & 9 & 12 & $x$ & Y & $100 \%$ & $100 \%$ & $100 \%$ \\
\hline 4 & 16 & 19 & 14 & 14 & 24 & 25 & 13 & 16 & 29 & 32.2 & 14 & 14 & 11 & 12 & 8 & 8 & 10 & 11 & $x$ & $x$ & $100 \%$ & $100 \%$ & $100 \%$ \\
\hline 5 & 15 & 15 & 17 & 18 & 21 & 21 & 15 & 15 & 29 & 29 & 14 & 21 & 12 & 13 & 8 & 12 & 10 & 12 & $x$ & $Y$ & $100 \%$ & $100 \%$ & $100 \%$ \\
\hline 6 & 15 & 17 & 16 & 16 & 19 & 22 & 13 & 13 & 28 & 30 & 13 & 18 & 12 & 12 & 9 & 11 & 12 & 13 & $X$ & $Y$ & $100 \%$ & $100 \%$ & $100 \%$ \\
\hline 7 & 15 & 17 & 16 & 17 & 20 & 21 & 13 & 14 & 29 & 30 & 12 & 15 & 10 & 11 & 12 & 14 & 10 & 12 & $x$ & $x$ & $100 \%$ & $100 \%$ & $100 \%$ \\
\hline 8 & 16 & 17 & 16 & 17 & 23 & 23 & 15 & 17 & 29 & 31.2 & 11 & 14 & 10 & 12 & 12 & 13 & 11 & 11 & $x$ & $Y$ & $100 \%$ & $100 \%$ & $100 \%$ \\
\hline 9 & 14 & 15 & 16 & 17 & 19 & 21 & 14 & 14 & 28 & 29 & 16 & 17 & 12 & 12 & 12 & 12 & 8 & 11 & $x$ & $x$ & $100 \%$ & $100 \%$ & $100 \%$ \\
\hline 10 & 15 & 15 & 17 & 17 & 23 & 24 & 15 & 16 & 30 & 31.2 & 15 & 15 & 11 & 12 & 11 & 11 & 12 & 12 & $x$ & $x$ & $100 \%$ & $100 \%$ & $100 \%$ \\
\hline 11 & 14 & 15 & 14 & 17 & 20 & 22 & 13 & 14 & 29 & 29 & & 18 & 11 & 12 & & & 8 & 10 & $x$ & $x$ & $100 \%$ & $100 \%$ & \\
\hline 12 & 17 & 18 & 16 & 17 & 21 & 22 & 12 & 13 & 28 & 30 & 10 & 15 & 11 & 12 & 11 & 12 & 9 & 9 & $x$ & $Y$ & $100 \%$ & $100 \%$ & $100 \%$ \\
\hline 13 & 16 & 17 & 16 & 17 & 22 & 24 & 14 & 15 & 29 & 33.2 & 12 & 17 & 11 & 11 & 12 & 13 & 9 & 11 & $x$ & $Y$ & $100 \%$ & $100 \%$ & $100 \%$ \\
\hline 14 & 14 & 17 & 15 & 19 & 20 & 22 & 13 & 14 & 29 & 30 & 13 & 15 & 11 & 12 & 11 & 11 & 9 & 10 & $x$ & $Y$ & $100 \%$ & $100 \%$ & $100 \%$ \\
\hline 15 & 15 & 17 & 14 & 17 & 24 & 26 & 10 & 13 & 30 & 32.2 & 12 & 13 & 11 & 12 & 9 & 10 & 9 & 13 & $x$ & $x$ & $100 \%$ & $100 \%$ & $100 \%$ \\
\hline 16 & 17 & 17 & 15 & 16 & 22 & 24 & 13 & 14 & 30 & 30 & 14 & 17 & 10 & 11 & 10 & 11 & 8 & 10 & $x$ & $x$ & $100 \%$ & $100 \%$ & $100 \%$ \\
\hline 17 & 16 & 17 & 14 & 18 & 21 & 22 & 12 & 15 & 30 & 30.2 & 11 & 14 & 11 & 12 & 9 & 10 & 8 & 10 & $x$ & $Y$ & $100 \%$ & $100 \%$ & $100 \%$ \\
\hline 18 & 17 & 17 & 16 & 18 & 20 & 24 & 11 & 12 & 30 & 30.2 & 17 & 17 & 9 & 11 & 11 & 12 & 12 & 12 & $x$ & $Y$ & $100 \%$ & $100 \%$ & $100 \%$ \\
\hline 19 & 15 & 16 & 17 & 18 & 23 & 23 & 15 & 15 & 31 & 32.2 & 14 & 15 & 10 & 12 & 11 & 13 & 10 & 12 & $x$ & $x$ & $100 \%$ & $100 \%$ & $100 \%$ \\
\hline 20 & 15 & 17 & 14 & 17 & 19 & 20 & 14 & 15 & 30 & 31 & 12 & 15 & 12 & 13 & 10 & 11 & 11 & 11 & $x$ & $x$ & $100 \%$ & $100 \%$ & $100 \%$ \\
\hline
\end{tabular}

The first column shows the sample ID number of the 20 individuals tested. The next 10 columns show the 10 loci tested for genotyping, which were D3S1358, D5S818, D7S820, D8S1179, D13S317, D18S51, D21S11, FGA, vWA, and Amelogenin. Each locus consists of two parental alleles (columns 1 and 2). The numbers in each box refer to the number of short tandem repeat (STR) sequences. For example, the genotype of individual number 1, locus D3S1358, is heterozygous for 14 and 16 STR repeats. The small table on the right shows the percentage genotype concordance with the genomic DNA control for the biological specimens tested. (WB) Whole blood; (FP) finger stick; (BS) buccal swab.

samples were obtained from the Human Caucasian Variation Panel (reference number HD100CAU) obtained from Coriell Cell Repositories. Human genomic DNA was also obtained from Promega Corporation for use as the standard in TaqMan assays.

\section{Genomic DNA Extraction From Human Whole Blood}

A 10- $\mu \mathrm{L}$ aliquot of human whole blood was used for extracting genomic DNA using the DNeasy Tissue Kit (QIAGEN). Thiophosphate-modified random hexamer $\left(5^{\prime}-\mathrm{NpNpNpNp}^{\mathrm{s}} \mathrm{Np}^{\mathrm{s}} \mathrm{N}-\right.$ $\left.3^{\prime}\right)$ was synthesized at Molecular Staging on a Perseptive Biosystems 8909 Expedite Nucleic Acid Synthesis System using standard $\beta$-cyanoethyl phosphoramidite coupling chemistry. Randomization was carried out as described (Beaucage et al. 2001). Phosphorothioate oxidation of the two 3'-terminal nucleotides was carried out using Beaucage sulfurizing reagent (Glen Research). \$29 DNA polymerase was from Amersham Biosciences (ABC), and yeast pyrophosphatase was from Roche Applied Science. Restriction endonucleases were from New England Biolabs. DNA size markers (100-bp DNA ladder, 1-kb DNA ladder) were from Invitrogen Life Technologies.

\section{Amplification of Human Genomic DNA by MDA}

Reactions of $100 \mu \mathrm{L}$, assembled in $0.2-\mathrm{ml}$ tubes, contained 10 ng of human genomic DNA; 37 mM Tris- $\mathrm{HCl}$ (pH 7.5); $50 \mathrm{mM}$ $\mathrm{KCl} ; 10 \mathrm{mM} \mathrm{MgCl} 2 ; 5 \mathrm{mM}\left(\mathrm{NH}_{4}\right)_{2} \mathrm{SO}_{4} ; 1 \mathrm{mM}$ dATP, dTTP, dCTP, and dGTP; $50 \mu \mathrm{M}$ exonuclease-resistant hexamer; 1 unit/mL yeast pyrophosphatase; and 800 units/mL $\$ 29$ DNA polymerase. Reactions were incubated at $30^{\circ} \mathrm{C}$ for $16 \mathrm{~h}$ and terminated by heating to $65^{\circ} \mathrm{C}$ for $3 \mathrm{~min}$. The double-stranded DNA concentration of the MDA product was measured using the Picogreen assay (Molecular Probe) according to the manufacturer's instructions. The authors have independently veri- fied the manufacturer's claim that the $1 \mathrm{mM}$ dNTPs and 50 $\mu \mathrm{M}$ single-stranded primers that are in the MDA reaction are not detected by the Picogreen reagent purchased (data not shown).

\section{Cell Lysis Procedure}

\section{Human Blood}

Extractions were assembled on ice; $34 \mu \mathrm{L}$ of $1 \times$ PhosphateBuffered Saline (PBS) was added to a tube containing $1 \mu \mathrm{L}$ of blood. Next $35 \mu \mathrm{L}$ of cell lysis solution ( $400 \mathrm{mM} \mathrm{KOH}, 10 \mathrm{mM}$ EDTA at pH 8.0, and $50 \mathrm{mM}$ Dithiothreitol) was added, mixed briefly, and incubated on ice for $10 \mathrm{~min}$. Then $35 \mu \mathrm{L}$ of neutralization solution ( $800 \mathrm{mM}$ Tris-hydrochloride) was added and mixed by vortexing for $5 \mathrm{sec}$. Of this lysate, $5 \mu \mathrm{L}$ was used per $100 \mu \mathrm{L}$ of MDA reaction carried out as described above.

\section{Buffy Coat}

Samples were prepared by centrifugation of a BD Vacutainer $\mathrm{K}_{3}$ EDTA tube (Becton Dickinson) with $5 \mathrm{~mL}$ of whole blood at $1000 \mathrm{~g}$ for $15 \mathrm{~min}$. Then $600 \mu \mathrm{L}$ of buffy coat was transferred from the white interface layer between the plasma and the red blood cells (Rees and Gough 1968) and stored at $-20^{\circ} \mathrm{C}$ until use. About $1 \mu \mathrm{L}$ of buffy coat was scraped from a frozen buffy coat sample with a pipette tip and added to a tube by rinsing into $34 \mu \mathrm{L}$ of $1 \times$ PBS. Then $35 \mu \mathrm{L}$ of cell lysis solution was added and treated as for whole blood. A 5- $\mu \mathrm{L}$ aliquot of lysed buffy coat was used per $100 \mu \mathrm{L}$ of MDA reaction.

\section{Buccal Swab}

Briefly, the subjects abstained from drinking coffee for $1 \mathrm{~h}$ with the mouth rinsed twice with water before swabbing. Buccal cells were collected by scrubbing a Catch-All Sample Col- 
lection Swab (Epicentre Technologies) firmly on the inside of the cheek $20 \times$ on both sides, making sure to scrub across the entire cheek. The swab tip was placed into a $1.5-\mathrm{mL}$ microcentrifuge tube containing $100 \mu \mathrm{L}$ of $1 \times$ PBS and vigorously twirled between the thumb and forefinger a minimum of 10 times. Finally, the tip was pressed against the inside wall of the tube to squeeze out the solution as much as possible before discarding the tip. Then $100 \mu \mathrm{L}$ of cell lysis solution was added to the buccal swab suspension and incubated on ice for $10 \mathrm{~min}$, before $100 \mu \mathrm{L}$ of neutralization buffer was added and mixed by vortexing for $5 \mathrm{sec}$. Of the lysed buccal swab, $5 \mu \mathrm{L}$ was used in $100-\mu \mathrm{L}$ MDA reactions.

\section{Short Tandem Repeat (STR) Loci Genotyping}

STR genotyping analysis was performed by Genaissance Pharmaceuticals using the AmpFLSTR Profiler Plus ID PCR Amplification Kit (Applied Biosystems), which amplifies nine tetranucleotide short tandem repeat (STR) loci and the Amelogenin locus in a single reaction tube. The 9 STR loci amplified are D3S1358, D5S818, D7S820, D8S1179, D13S317, D18S51, $D 21 S 11, F G A$, and $v W A$. Each multiplex STR genotyping reaction was performed in $5 \mu \mathrm{L}$, and $0.5 \mathrm{ng}$ of MDA-amplified DNA was added per reaction.

\section{Genotyping of Amplification Products by the TaqMan Assay for Allelic Discrimination}

Genotyping analysis on SNPs CYP2C19*2, CYP2D6*8, CYP2C19*3, CYP2D6*6, and CYP2D6* 4 was performed using the TaqMan assay for allelic discrimination (Applied Biosystems). TaqMan analysis was performed using the ABI 7000 sequence detector system according to the manufacturer's specifications (Applied Biosystems). Each SNP TaqMan reaction was performed in $25 \mu \mathrm{L}$, and $100 \mathrm{ng}$ of MDA-amplified DNA was added per reaction.

\section{Quantitative PCR Analysis of Amplification Products}

TaqMan analysis was performed using the ABI 7700 sequence detector system according to the manufacturer's specifications (Applied Biosystems). The TaqMan reaction consists of $50 \mu \mathrm{L}$ of $1 \times$ Platinum Taq Polymerase Buffer, $5 \mathrm{mM} \mathrm{MgCl}_{2}, 1$ $\mathrm{mM}$ each dNTP, $1 \mu \mathrm{L}$ ROX Reference Dye (Invitrogen Life Technologies), 1 unit of Platinum Taq Polymerase (Invitrogen Life Technologies), $0.3 \mu \mathrm{M}$ each of forward and reverse PCR primers, $0.25 \mu \mathrm{M}$ FAM/TAMRA fluorescent/quencher probe, and $1 \mu \mathrm{g}$ of MDA-amplified DNA. Purified human genomic DNA (gDNA; Promega) was used to generate a standard curve of $0,0.001,0.01,0.1$, and $1 \mu \mathrm{g}$ gDNA to quantify the MDAamplified DNA. Loci representation (MDA/gDNA) is reported as a percentage and is derived as 100(loci copy number/ microgram of MDA product)/(loci copy number/microgram of gDNA). A value of $100 \%$ indicates that the loci copy number for the amplified DNA is equal to the loci copy number for the unamplified genomic DNA. The 47 loci examined and their chromosome assignments are depicted in Table 1. TaqMan assays for eight additional loci used to compare blood, buccal swabs, buffy coat, and Guthrie cards were carried out as described (Dean et al. 2002).

\section{ACKNOWLEDGMENTS}

The publication costs of this article were defrayed in part by payment of page charges. This article must therefore be hereby marked "advertisement" in accordance with 18 USC section 1734 solely to indicate this fact.

\section{NOTE ADDED IN PROOF}

While this paper was in press, Lage et al. reported that MDA generated bias in amplified DNA used for CGH analysis (Lage et al. 2003). We note that the authors used only $1 / 8^{\text {th }}$ of the
\$29 DNA polymerase detailed in our publication (Dean et al. 2002). We have previously observed that use of less $\phi 29$ polymerase results in incomplete coverage.

\section{REFERENCES}

Beaucage, S.L., Bergstrom, D.E., Glick, G.D., and Jones, R.A. 2001. Current protocols in nucleic acid chemistry. John Wiley, New York, NY.

Blanco, L., Bernad, A., Lazaro, J.M., Martin, G., Garmendia, C., and Salas, M. 1989. Highly efficient DNA synthesis by the phage $\phi 29$ DNA polymerase. Symmetrical mode of DNA replication. J. Biol. Chem. 264: 8935-8940.

Cheung, V.G. and Nelson, S.F. 1996. Whole-genome amplification using a degenerate oligonucleotide primer allows hundreds of genotypes to be performed on less than one nanogram of genomic DNA. Proc. Natl. Acad. Sci. 93: 14676-14679.

Davies, H., Bignell, G.R., Cox, C., Stephens, P., Edkins, S., Clegg, S., Teague, J., Woffendin, H., Garnett, M.J., Bottomley, W., et al. 2002. Mutations of the BRAF gene in human cancer. Nature 417: 949-954.

Dean, F.B., Nelson, J.R., Giesler, T.L., and Lasken, R.S. 2001. Rapid amplification of plasmid and phage DNA using $\$ 29$ DNA polymerase and multiply-primed rolling circle amplification. Genome Res. 11: 1095-1099.

Dean, F.B., Hosono, S., Fang, L., Wu, X., Faruqi, A.F., Bray-Ward, P. Sun, Z., Zong, Q., Du, Y., Du, J., et al. 2002. Comprehensive human genome amplification using multiple displacement amplification. Proc. Natl. Acad. Sci. 99: 5261-5266.

Dunning, A.M., Talmud, P., and Humphries, S.E. 1988. Errors in the polymerase chain reaction. Nucleic Acids Res. 16: 10393.

Eckert, K.A. and Kunkel, T.A. 1991. DNA polymerase fidelity and the polymerase chain reaction. PCR Methods Appl. 1: 17-24.

Emmert-Buck, M.R., Bonner, R.F., Smith, P.D., Chuaqui, R.F., Zhuang, Z., Goldstein, S.R., Weiss, R.A., and Liotta, L.A. 1996. Laser capture microdissection. Science 274: 998-1001.

Esteban, J.A., Salas, M., and Blanco, L. 1993. Fidelity of $\phi 29$ DNA polymerase. Comparison between protein-primed initiation and DNA polymerization. J. Biol. Chem. 268: 2719-2726.

Euhus, D.M., Cler, L., Shivapurkar, N., Milchgrub, S., Peters, G.N., Leitch, A.M., Heda, S., and Gazdar, A.F. 2002. Loss of heterozygosity in benign breast epithelium in relation to breast cancer risk. J. Natl. Cancer Inst. 94: 858-860.

Harty, L.C., Garcia-Closas, M., Rothman, N., Reid, Y.A., Tucker, M.A., and Hartge, P. 2000. Collection of buccal cell DNA using treated cards. Cancer Epidemiol. Biomarkers Prev. 9: 501-506.

Higuchi, R. 1995. Simple and rapid preparation of samples for PCR. In PCR technology: Principles and applications for DNA amplification (ed. H. Erlich), pp. 31-38. Stockton Press, New York, NY.

Holding, C. and Monk, M. 1989. Diagnosis of $\beta$-thalassaemia by DNA amplification in single blastomeres from mouse preimplantation embryos. Lancet 2: 532-535.

Lage, J.M., Leamon, J.H., Pejovic, T., Hamann, S., Lacey, M., Dillon, D., Seagraves, R., Vossbrinck, B., Gonzalez, A., and Pinkel, D. 2003. Whole-genome analysis of genetic alterations in small DNA samples using hyperbranched strand displacement amplification and array-CGH. Genome Res. 13: 294-307.

Li, H.H., Gyllensten, U.B., Cui, X.F., Saiki, R.K., Erlich, H.A., and Arnheim, N. 1988. Amplification and analysis of DNA sequences in single human sperm and diploid cells. Nature 335: 414417.

Nelson, J.R., Cai, Y.C., Giesler, T.L., Farchaus, J.W., Sundaram, S.T., Ortiz-Rivera, M., Hosta, L.P., Hewitt, P.L., Mamone, J.A., Palaniappan, C., et al. 2002. TempliPhi, \$29 DNA polymerase based rolling circle amplification of templates for DNA sequencing. Biotechniques Suppl: $44-47$.

Patil, N., Berno, A.J., Hinds, D.A., Barrett, W.A., Doshi, J.M., Hacker, C.R., Kautzer, C.R., Lee, D.H., Marjoribanks, C., McDonough, D.P., et al. 2001. Blocks of limited haplotype diversity revealed by high-resolution scanning of human Chromosome 21. Science 294: $1719-1723$.

Paunio, T., Reima, I., and Syvanen, A.C. 1996. Preimplantation diagnosis by whole-genome amplification, PCR amplification, and solid-phase minisequencing of blastomere DNA. Clin. Chem. 42: $1382-1390$.

Pollock, P.M. and Meltzer, P.S. 2002. Lucky draw in the gene raffle. Nature 417: 906-907. 


\section{Hosono et al.}

Rees, G. and Gough, R. 1968. Buffy-coat preparation from fresh whole blood. J. Med. Lab. Technol. 25: 117-118.

Saiki, R.K., Gelfand, D.H., Stoffel, S., Scharf, S.J., Higuchi, R., Horn, G.T., Mullis, K.B., and Erlich, H.A. 1988. Primer-directed enzymatic amplification of DNA with a thermostable DNA polymerase. Science 239: 487-491.

Smit, A.F. 1996. The origin of interspersed repeats in the human genome. Curr. Opin. Genet. Dev. 6: 743-748.

Telenius, H., Carter, N.P., Bebb, C.E., Nordenskjold, M., Ponder, B.A., and Tunnacliffe, A. 1992. Degenerate oligonucleotide-primed PCR: General amplification of target DNA by a single degenerate primer. Genomics 13: 718725.

Ullu, E. and Tschudi, C. 1984. Alu sequences are processed 7SL RNA genes. Nature 312: 171-172.

Weiner, A.M. 1980. An abundant cytoplasmic 7S RNA is complementary to the dominant interspersed middle repetitive
DNA sequence family in the human genome. Cell 22: 209218.

Zhang, L., Cui, X., Schmitt, K., Hubert, R., Navidi, W., and Arnheim, N. 1992. Whole-genome amplification from a single cell: Implications for genetic analysis. Proc. Natl. Acad. Sci.

89: $5847-5851$.

\section{WEB SITE REFERENCES}

http://www-genome.wi.mit.edu/snp/human/; WIAF (Whitehead Institute-Affymetrix) SNPs database.

Received September 17, 2002; accepted in revised form January 29, 2003.

\section{Genome Research}




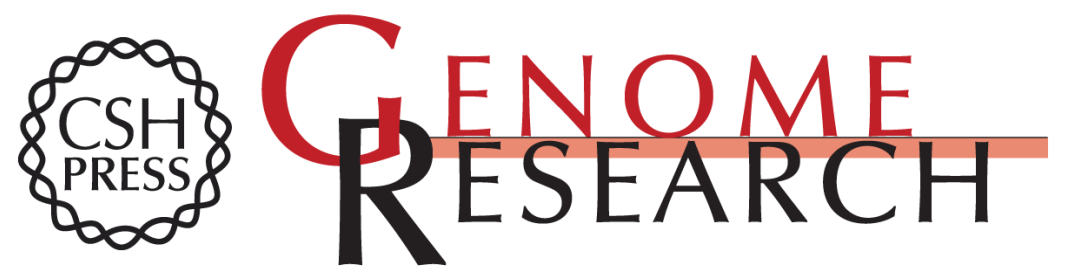

\section{Unbiased Whole-Genome Amplification Directly From Clinical Samples}

Seiyu Hosono, A. Fawad Faruqi, Frank B. Dean, et al.

Genome Res. 2003 13: 954-964

Access the most recent version at doi:10.1101/gr.816903

References This article cites 24 articles, 12 of which can be accessed free at:

http://genome.cshlp.org/content/13/5/954.full.html\#ref-list-1

\section{License}

Email Alerting Receive free email alerts when new articles cite this article - sign up in the box at the Service top right corner of the article or click here.

\section{Affordable, Accurate Sequencing.}

To subscribe to Genome Research go to: https://genome.cshlp.org/subscriptions 